OPEN ACCESS

Edited by:

Peter Groffman,

City University of New York,

United States

Reviewed by:

Kim Yriälä,

Zhejiang Agriculture and Forestry

University, China

Florentin Constancias,

Centre de Coopération Internationale

en Recherche Agronomique pour le

Développement (CIRAD), France

*Correspondence:

Sofie Thijs

sofie.thijs@uhasselt.be

Specialty section:

This article was submitted to

Terrestrial Microbiology,

a section of the journal

Frontiers in Microbiology

Received: 29 November 2018 Accepted: 18 March 2019

Published: 04 April 2019

Citation:

Espenshade J, Thijs S,

Gawronski S, Bové H, Weyens N and

Vangronsveld J (2019) Influence

of Urbanization on Epiphytic Bacterial Communities of the Platanus $x$

hispanica Tree Leaves in a Biennial Study. Front. Microbiol. 10:675. doi: 10.3389/fmicb.2019.00675

\section{Influence of Urbanization on Epiphytic Bacterial Communities of the Platanus x hispanica Tree Leaves in a Biennial Study}

\author{
Jordan Espenshade ${ }^{1}$, Sofie Thijs ${ }^{1 *}$, Stanislaw Gawronski², Hannelore Bové 1,3,4, \\ Nele Weyens ${ }^{1}$ and Jaco Vangronsveld ${ }^{1,5}$
}

${ }^{1}$ Centre for Environmental Sciences, Hasselt University, Diepenbeek, Belgium, ${ }^{2}$ Faculty of Horticulture, Biotechnology and Landscape Architecture, Warsaw University of Life Sciences, Warsaw, Poland, ${ }^{3}$ Biomedical Research Institute, Hasselt University, Diepenbeek, Belgium, ${ }^{4}$ Centre for Surface Chemistry and Catalysis, KU Leuven, Leuven, Belgium, ${ }^{5}$ Department of Plant Physiology, Faculty of Biology and Biotechnology, Maria Curie-Skłodowska University, Lublin, Poland

The aerial surfaces of plants harbor diverse communities of microorganisms. The rising awareness concerning the potential roles of these phyllosphere microbiota for airborne pollutant remediation and plant growth promotion, advocates for a better understanding of their community structure and dynamics in urban ecosystems. Here, we characterized the epiphytic microbial communities on leaves of Platanus $\times$ hispanica trees in the city centre of Hasselt (Belgium), and the nearby forest area of Bokrijk, Genk (Belgium). We compared the influences of season, site, and air pollutants concentration variations on the tree's phyllosphere microbiome by determining the intra- and inter-individual variation in leaf bacterial communities. High-throughput amplicon sequencing of the $16 S$ rRNA gene revealed large variation in the bacterial community structure and diversity throughout the years but also allowed to discriminate an environment effect on community assembly. Partial drivers for this environment effect on composition can be correlated with the huge differences in ultrafine particulate matter (UFP) and black carbon on the leaves. A change in bacterial community composition was noted for trees growing in the city center compared to the natural site, and also more human-associated genera were found colonizing the leaves from the city center. These integrated results offer an original and first insight in the Platanus phyllomicrobiota, which can offer new opportunities to use phyllosphere microorganisms to enhance air pollution degradation.

Keywords: urban microbiome, phyllosphere-inhabiting bacteria, phylloremediation, biodiversity, plant-microbe interactions, particulate matter, black carbon

\section{INTRODUCTION}

Microorganisms associated with the aerial structures of plants, otherwise known as the phyllosphere, are receiving greater attention in urban microbiome research (King, 2014). An important part of future urban planning is minimizing environmental degradation for the health and safety of the residents. The "biodiversity hypothesis" connects evidence between the rise of non-communicable diseases in urbanized populations to the decrease of environmental 
biodiversity (Haahtela et al., 2013; Rook, 2013). In 2018, 55\% of the world's population live in urban environments and this is expected to increase in the future with rising population growth (United Nations, 2018). In China, already $60 \%$ of its population lives in cities, and more than 100 Chinese cities count above 1 million people (The Guardian, 2017). Urban residents are more likely to be exposed to higher levels of air pollution, amongst which traffic related sources of pollution contribute an important part, and which leads to lung and cardiovascular diseases and premature death. In the past few years, several European cities have tried to regulate the volume or type of vehicles allowed within the city limits, but annual concentrations of air pollution continue to exceed the WHO guidelines (Holman et al., 2015). Besides regulation, plans to mitigate exposure to air pollution and to promote urban green coverage for scavenging airborne pollutants (fine dust, soot particles, PAHs) each represent important efforts to combat this ubiquitous problem.

To enhance the capacity of vegetation to intercept airborne pollutants, the selection of both the appropriate plant species and their associated phyllospheric microbiome are important, as both influence the performance of phylloremediation (Weyens et al., 2015). Depending on the species, many plants have the physical characteristics to capture significant amounts of particulate matter (PM), thereby improving local air quality (Sæbø et al., 2012; Nowak et al., 2013; Popek et al., 2013). Phyllospheric microorganisms can enhance this pollutant sequestration effect by improving plant growth and health, via various direct and indirect mechanisms such as stress reduction by interfering with plant ethylene levels, improving drought resistance, improving protection from herbivore stress, salinity, and promoting plant growth through the synthesis of plant-growth hormones, and improving nutrient uptake (Vorholt, 2012; Weyens et al., 2015; Saleem et al., 2017). In addition, epiphytic microorganisms can enhance xenobiotic pollutant transformations ex planta and contribute to nutrient uptake and conversion, while the endophytic community is important for transforming organic compounds in planta, thus reducing their toxicity (Barac et al., 2004; Taghavi et al., 2005; Weyens et al., 2009a,b; Afzal et al., 2014). The contribution of the phyllosphere microbiome to air pollutant degradation via oxidation mechanisms has been highlighted recently in Weyens et al. (2015). Furthermore, outdoor plants are a useful source of microbes for local dispersal and emigration to the built environment (Miletto and Lindow, 2015; Lymperopoulou et al., 2016; Leung et al., 2018). Sustaining a diverse microbiome on plants outdoors can have a potentially positive outcome on the health of citizens, similarly, to the role of plants indoor (Berg et al., 2014).

Despite the fact that the relationship between urban plants and their associated microbiota has many potential health benefits, only a few studies have attempted to explore the vast diversity of these communities. Still fewer studies have addressed the changes in Platanus leaf bacterial communities in response to air pollution (Zhang et al., 2015; Gandolfi et al., 2017). In complex environments like the city, it is unclear how microbial community dynamics vary in response to a multitude of changing environmental factors, the addition of human-associated microbes, and the rising level of exposure to aerosolized pollution.

To address this knowledge gap, this study seeks to characterize the Platanus $\times$ hispanica (colloquially referred to as London Plane) phyllospheric microbiome across a gradient of urbanization and traffic density and associated differences in local air quality, in the region of Hasselt, Belgium. A chronosequence sampling was performed in 2014 and 2016 to allow for a 2-year comparison. In addition, multiple metadata were gathered and measured such as ultrafine particles and black carbon to characterize the exposure of each location to common representative components of vehicular-related air pollution.

\section{MATERIALS AND METHODS}

\section{Sample Collection}

Platanus $\times$ hispanica trees at three locations were chosen around Hasselt, Belgium for sampling based on the local urban characteristics and adjacent traffic patterns, which were observed visually. Hasselt is a city of $102.24 \mathrm{~km}^{2}$ with a population of 77.000 inhabitants. Live air pollution data are monitored and available on the VMM website. The year average PM2.5 concentrations are $15 \mu \mathrm{g} / \mathrm{m}^{3}$ (VMM). Mothers and their newborns in the city of Hasselt and nearby city of Genk have the ability to participate in the ENVIRONAGE birth cohort study, in which the effect of UFP exposure and black carbon on human health is investigated (Janssen et al., 2017, see also Figure $\mathbf{1}$ therein for a Corine land cover and main road map of Hasselt). At each of the three locations, adult trees were sampled (see Google street view for the general tree morphology and environment). The "Rural" tree (50.969 $\mathrm{N} ; 5.408 \mathrm{E})$ was located in the arboretum of Domein Bokrijk which has a low burden of urbanization and road traffic. The "Intersection" tree $(50.930 \mathrm{~N}$; $5.360 \mathrm{E})$ was located at a major intersection outside of the city proper; it represents lower urban intensity and has a high road traffic burden. The "Inner-city" tree $(50.932 \mathrm{~N} ; 5.347 \mathrm{E})$ was located within the city proper; it represents a higher urban intensity but has a lower road traffic burden compared to the Intersection. None of the trees chosen receive any type of annual maintenance such as pollarding or crowning.

In early May 2014 and 2016, we collected leaves with ethanol sterilized gloves from four equidistant points around each tree at an approximate height of 3-4 ms, which was judged by the length of our cutting tool and near to the bottom of all trees sampled. Each of the four replicate samples consisted of three leaves from the same stem and weighed approximately $2.5 \mathrm{~g}$. The sample leaves were transferred into sterile falcon tubes with $20 \mathrm{ml}$ of $10 \mathrm{mM} \mathrm{MgSO}_{4}$ solution and transported to lab.

At each location, ultra-fine particles (UFP, $<1.0 \mu \mathrm{m}$ diameter) were measured with an Aerasense Nanomonitor (Philips, Amsterdam, Netherlands) during the same hours as the leaf sampling took place and additional leaves were collected to determine their black carbon (BC) content. We took the land-use classifications for each location from the 2012 CORINE Land Cover database (European Union, 2018). 

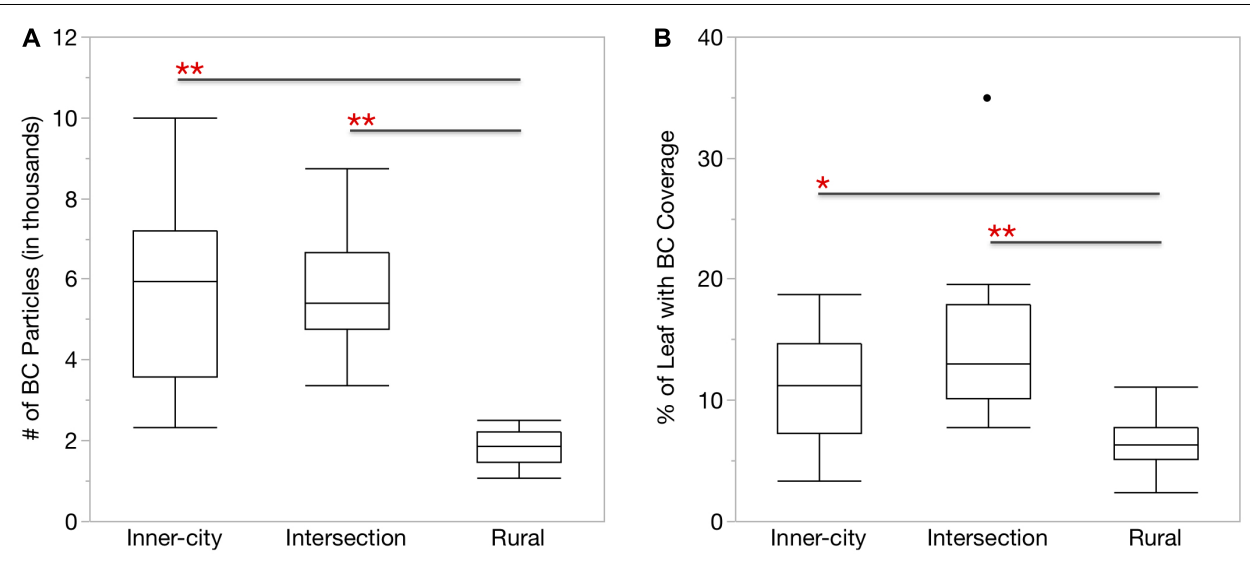

FIGURE 1 | More BC particles were found on the surface of urban Platanus $\times$ hispanica leaves. Box plots show (A) the number of BC particles per mm ${ }^{2}$ leaf segment and $\mathbf{( B )}$ the percentage of the total leaf area covered by BC particles. ${ }^{*} p<0.01,{ }^{* *} p<0.0001$. Box plots display the median, the first and third quartiles, and the maximum and minimum $n=18$.

\section{Black Carbon Content Determination Image Acquisition}

The black carbon (BC) content of the leaves was determined by a specific and sensitive technique especially designed to quantify carbonaceous particles based on the non-incandescence-related white-light generation of those particles under femtosecond pulsed illumination as published before (Bové et al., 2016). For this, a Zeiss LSM 510 META NLO (Carl Zeiss, Jena, Germany) mounted on an Axiovert 200M equipped with a two-photon femtosecond pulsed laser (MaiTai DeepSee, Spectra-Physics, United States; $810 \mathrm{~nm}, 150$ femtoseconds, $80 \mathrm{MHz}, 10 \mathrm{~mW}$ laser power on the sample) was used. Three, $1 \times 1 \mathrm{~cm}^{2}$ squares were cut from the left, right, and top of two leaves for each location and taped on coverslips with the adaxial side facing downward for imaging. Z-stacks were taken, using a 10x/0.3 (Plan-Neofluar) objective, throughout the plant tissue sections containing approximately 25 images with a size of $900 \times 900 \times 318 \mu \mathrm{m}^{3}\left(1.8 \times 1.8 \times 6.6 \mu \mathrm{m}^{3}\right.$ pixel size and $3.2 \mu$ s pixel dwell time). White-light from the BC particles was acquired in the non-descanned mode after spectral separation and emission filtering employing a $400-410 \mathrm{~nm}$ band-pass filter. Simultaneously, the autofluorescence from the leaves were captured using a $450-650 \mathrm{~nm}$ band pass filter. Three randomly chosen $\mathrm{z}$-stacks are made per tissue biopsy and three biopsies are taken per leaf and two leaves per location. Hence, in total per location, 18 technical replicates were included in the analysis.

\section{Image Analysis}

The number and total area of $\mathrm{BC}$ particles in the acquired $\mathrm{z}$-stacks were determined using an automated and customized Matlab program (Matlab, 2013, Mathworks, Netherlands). First, a maximum project of the $z$-stack is performed. Next a peak-find algorithm counts connected pixels above a threshold value of $1.28 \%$ (manually validated using Fiji; Image J v 2.0, Open source software), which removes background signals. In the end, two output metrics were defined: (i) the total number of detected $\mathrm{BC}$ particles per square millimeter leaf and (ii) the percentage of leaf area covered with particles, i.e., total area of $\mathrm{BC}$ particles normalized over the imaged area of the leaf.

\section{Sample Preparation and DNA-Extraction}

To release the epiphytic bacteria from the surface, sample leaves in $20 \mathrm{ml}$ of $10 \mathrm{mM} \mathrm{MgSO} 4$ were vortexed on high for $2 \mathrm{~min}$. The leaves were removed and the epiphyte solution was split into three aliquots which were passed through three sterile $0.2 \mu \mathrm{m}$ nitrocellulose filters (Merck, Darmstadt, Germany). Each filter was transferred to a separate $2 \mathrm{ml}$ bead beating tube with $0,1 \mathrm{~mm}$ glass beads (MoBio, Carlsbad, CA, United States) to release the epiphytes by shaking into Lysis Buffer P solution from the Invisorb Spin Plant Mini Kit (Stratec Molecular, Berlin, Germany). The lysis buffer was transferred to a new tube and gDNA was extracted with the kit according to manufacturer's instructions, utilizing the Prefilter to remove excess glass beads and plant material.

\section{Preparation of 16S Library for Sequencing With Illumina MiSeq Amplification of Target Sequences}

The three gDNA extraction replicates obtained from each leaf sample were amplified separately with the following 16S rRNA gene primers. The first round of PCR targeted the V5-V7 region with primers 799F (5'-AACMGGATTAGATACCCKG-3', Chelius and Triplett, 2001) and 1391R (5'-GACGGGCGGTGWGTRCA-3', Walker and Pace, 2007) to minimize amplification of non-target rDNA from the leaf cells (Beckers et al., 2016). Initial denaturation at $95^{\circ} \mathrm{C}$ for $2 \mathrm{~min}, 32$ cycles of $95^{\circ} \mathrm{C}$ for $30 \mathrm{~s}, 55^{\circ} \mathrm{C}$ for $90 \mathrm{~s}$, $72^{\circ} \mathrm{C}$ for $45 \mathrm{~s}$, and a final extension of $72^{\circ} \mathrm{C}$ for $7 \mathrm{~min}$. Round one PCR products were separated on a $1.5 \%$ agarose gel to exclude the larger mitochondrial $18 \mathrm{~S}$ fragment $(\sim 1000 \mathrm{bp})$ and leftover primers. The $16 \mathrm{~S}$ bands were removed with $\mathrm{x}$-tracta ${ }^{\mathrm{TM}}$ Gel Extractors (Promega Corporation, Madison, WI, United States) and cleaned with QIAquick Gel Extraction Kit (Qiagen, Venlo, Netherlands). 
A second, shorter PCR used 2-4 $\mu$ l of the previous amplicons to target the same region with $799 \mathrm{~F}$-ad (5' TCGTCGGCAGCGTCAGATGTGTATAAGAGACAGAACMG GATTAGATACCCKG-3') and 1193R-ad (5'-GTCTCGTGGG CTCGGAGATGTGTATAAGAGACAGACGTCATCCCCACCT TCC-3', based on Bodenhausen et al., 2013). Primers were obtained from Biolegio (Nijmegen, Netherlands) with the Illumina adaptors added to the $5^{\prime}$ end, primer sequence region is underlined. Initial denaturation at $95^{\circ} \mathrm{C}$ for $2 \mathrm{~min}, 25$ cycles of $95^{\circ} \mathrm{C}$ for $30 \mathrm{~s}, 55^{\circ} \mathrm{C}$ for $30 \mathrm{~s}, 72^{\circ} \mathrm{C}$ for $45 \mathrm{~s}$, and a final extension of $72^{\circ} \mathrm{C}$ for $5 \mathrm{~min}$. Fast Start HiFi (Roche Applied Science, Mannheim, Germany) components were used for all PCR amplifications. 0.5 and $0.4 \mu \mathrm{M}$ of each primer was used in the first and second PCR, respectively. $25 \mu \mathrm{l}$ reaction volumes had $1 \times$ reaction buffer with $1.8 \mathrm{mM} \mathrm{MgCl} 2$ included, $0.2 \mathrm{mM}$ of each Roche dNTP, and 1.5 U Roche High-Fidelity Taq polymerase.

\section{Preparation of the 16S Amplicon Library}

The amplicons resulting from each set of extraction replicates $(n=3)$ were combined prior to barcoding the samples. Unique combinations of Nextera XT index kit (Illumina, San Diego, CA, United States) were attached to the $5^{\prime}$ and $3^{\prime}$ ends of each individual library, following the method used by Coretti et al. (2017). Subsequently, the barcoded samples were cleaned-up with AMPure XP beads (Agencourt Bioscience, United States) and the individual DNA libraries were quantified with Quantifluor dsDNA (Promega Corporation, Madison, WI, United States). Equimolar concentrations of each sample were pooled, and the final pooled library was sent to Macrogen (Macrogen Korea, Seoul, South Korea) for sequencing on the Illumina MiSeq platform with a $300 \mathrm{bp}$ pairedend protocol.

\section{Data Analysis of 165 Amplicon Sequences}

Prior to delivery, sequences were trimmed by Macrogen with Scythe (v.994) and Sickle to remove the adapter sequence and reads less than $36 \mathrm{bp}$. Remaining reads were then quality filtered and chimera checked with DADA2 v 1.8 (Callahan et al., 2016). The resulting ASV table and representative sequences were imported as artifacts to Qiime 2 (Gregory Caporaso et al., 2010). To improve the accuracy of taxonomic classification, we extracted our 16S target region of 799F-1193R from the Silva v132 (Quast et al., 2013) 99\% data set and used these optimized reference sequences to train a custom Naïve Bayesian classifier on the majority_taxonomy_7 SILVA database. FastTree 2 (Price et al., 2010) generated rooted and unrooted phylogenetic trees after masked alignment of the reference sequences. All samples were rarefied to the lowest equal number of reads and we checked for adequate sampling depth with the Good's Coverage metric. Genera occurring in at least $75 \%$ of the replicate samples each year were included as part of each tree's persistent microbiome.

\section{Statistical Analysis}

\section{Bacterial Taxonomic Diversity}

Intra-tree diversity was assessed with ASV observations, Shannon diversity, Simpson diversity, and Faith's phylogenetic diversity.
Differences in intra-tree diversity between locations was tested with Kruskall-Wallis Rank Sum Test followed by the Pairwise Wilcoxon Rank Sum Test. Singletons were removed from the ASV table for all following analysis. Inter-tree diversity was assessed in R (R Development Core Team, 2018) utilizing the ape, phyloseq, ggplot2, vegan, RVAideMemoire packages (Paradis et al., 2004; McMurdie and Holmes, 2014; Oksanen, 2015; Wickham, 2016; Hervé, 2018). Bacterial community diversity was measured with the Bray-Curtis dissimilarity metric and visualized on a PCoA plot. We compared the community differences between tree locations and years with the adonis function from vegan (999 permutations), followed by the pairwise.perm.anova function from RVAideMemoire with FDR correction (999 permutations).

\section{Bacterial Functional Diversity}

The web-based metagenome inference tool Piphillin (Iwai et al., 2016) was used at the $97 \%$ identity cut-off to normalize $16 \mathrm{~S}$ ASV counts and assign KEGG orthologs and pathways (KEGG, May 2017 Release). Bacterial taxonomy and inferred KEGG pathways were analyzed with the Linear discriminant analysis Effect Size (LEfSe) tool (Segata et al., 2011) hosted on the Huttenhower Galaxy server (Afgan et al., 2018) to discover significant associations between the land class types. Pairwise comparisons were made between years and the Kruskal-Wallis sum rank and Wilcoxon signed rank-sum tests were both run at $p<0.05$. We also tested for differential abundance of the inferred KEGG orthologs between all groups using DESeq2 (Love et al., 2014) hosted on the Freiburg Galaxy server (Afgan et al., 2018). Orthologs were rounded to the nearest integer. Significant differences are those less than 0.05 after a Benjamini-Hochberg adjustment, which controls for false discoveries.

\section{Air Quality Characteristics}

We compared the average ultra-fine particle concentration and size with ANOVA and post hoc Tukey-Kramer HSD tests. Black carbon particles and leaf coverage were compared with the Kruskal-Wallis Rank Sum Test followed by the Pairwise Wilcoxon Rank Sum Test. All tests were done in JMP Pro 13 software (SAS Institute Inc., Buckinghamshire, United Kingdom).

\section{Data Deposit in NCBI}

All raw Illumina 16S rRNA gene sequencing data were submitted to NCBI SRA with project identifier PRJNA505409, and sample IDs SRX5015223 to SRX5015246.

\section{RESULTS}

\section{Sampling Site and Air Quality Characteristics}

To better understand the bacterial phyllosphere of Platanus $\times$ hispanica trees planted in urban centers and the effects which anthropogenic pressures may exert on these communities, we chose three locations of different urban density and traffic patterns from which to sample air quality and leaves. Hasselt is 
the capital city of the Limburg province in Belgium. According to open data on statbel.be, between 2014 and 2016, the municipal population rose from 76,000 to 77,000 inhabitants. Table 1 further describes the sampling sites, including the name we assigned each location to help differentiate between the trees, the coordinates and land use class in which each tree stands, and the distance from each tree to the nearest road. The average UFP per $\mathrm{cm}^{3}$ and average UFP size in nanometers are also listed in Table $\mathbf{1}$.

Air sampled at the urban locations, i.e., the inner-city and intersection sites, had significantly higher concentrations of UFP on average than the rural location $(p<0.001)$, but with no significant difference between each other. However, particle size did change based on location. Compared to the innercity site, the rural position had significantly larger particles $(p<0.001)$ and the intersection location had significantly smaller particles $(p<0.001)$.

Similar to the UFP in the air, the urban leaves also had more $\mathrm{BC}$ particles than the rural leaves (Figure 1A). When accounting for the difference in surface area, the urban leaves also had a greater percentage of area covered by the BC particles (Figure 1B).

\section{Phyllospheric Bacterial Community Structure}

After quality filtering, our $16 \mathrm{~S}$ amplicon data set consisted of 178,908 sequences, ranging from 2,907 to 34,895 sequences per sample. In an effort to keep all 24 samples in the dataset, rarefaction was set to the lowest number of reads and subsequently checked with Good's coverage index. The average sample coverage was 0.99 ( $\pm 0.001 \mathrm{SE}$ ), which was deemed sufficient to continue with all samples included in further analysis.

The rarefied dataset represented bacterial communities from 17 phyla, 273 identified genera, and 1,502 ASVs. Overall, the most dominant phyla were Proteobacteria (71.5\%), Deinococcus-Thermus (16.9\%), Actinobacteria (4.5\%), and Firmicutes (1.9\%). These phyla were present on all trees in both sampling years and except for the Firmicutes which were missing in three of the eight Rural samples, these phyla were present in all samples.

Proteobacteria was the most abundantly identified phylum at all locations, however the phylum was more abundant in 2014 compared to 2016 (Figure 2). In 2014, Proteobacteria represented 93.4 and $86.8 \%$ of the rural and urban bacterial community, respectively. By 2016, the community structure had shifted to include more Deinococcus-Thermus bacteria, especially on the urban tree leaves (42.0\%) compare to the rural tree leaves (14.0\%). Even so, the Proteobacteria phylum still made up the majority of bacteria at each location. Other highly abundant phyla include the Actinobacteria (2.3-6.0\%), Firmicutes (0.6-3.3\%), Bacteroidetes (0.7-1.8\%) and FBP (0.8-2.5\%).

A closer look into the community structure at the level of genus illustrated not only the same temporal differences we saw on the phyla level, but also interesting similarities between the urban samples that are not in the rural samples (Figure 2). In 2014, the most abundant bacterial genus on the urban leaves was Escherichia-Shigella and in 2016 it was Deinococcus with an average relative abundance of $38.8 \%( \pm 0.5 \mathrm{SE})$. The most abundant genus of the rural tree in 2014 was Sphingomonas (28.3\%) and in 2016, unknown Enterobacteriaceae (25.3\%). The top ten most abundant genera at each tree account for more than three-quarters $(78.7 \% \pm 2.5 \mathrm{SE})$ of the total genera.

\section{Persistent Bacterial Genera of the Core Platanus $\times$ hispanica Leaf Microbiome}

At each tree location, bacterial genera that were persistently identified in the phyllosphere from one sampling year to another were compared between all three locations and we found eight genera are consistently shared across all trees (Figure 3). While this represents a small fraction of the overall diversity $(28 \%$ of all ASVs) it comprises a large portion $(60.9 \%)$ of the total reads.

The shared genera were Deinococcus* $(15.9 \%$ of total reads), Escherichia-Shigella (15.9\%), Sphingomonas* (12.1\%), Pseudomonas (5.9\%), 1174-901-12* (Family: Beijerinckiaceae, 5.4\%), Methylobacterium* (3.3\%), Acidiphilium (1.8\%), and Chryseobacterium $(0.6 \%)$. Of these six, only four genera, those denoted by “*”, were identified in $100 \%$ of the samples taken.

Between the intersection and inner-city sites, Friedmanniella was a persistently identified genus and between the intersection and rural leaves, Afipia was also persistent. The rural and inner-city locations did not share any more genera than those common to all three sites. However, the rural and inner-city leaves each had one genus unique to that location while the intersection leaves had four.

\section{Diversity of the Bacterial Communities}

There was no meaningful difference in observed species or phylogenetic diversity between the locations (Table 2). Although in 2014 the inner-city had slightly less diversity than the rural leaves (Simpson and Shannon $p=0.0304$ ), this was not the case in 2016. The phylogenetic diversity (Faith's PD) and observed ASV counts did not differ by location in both years.

TABLE 1 | Characteristics and UFP measurements at each of the Platanus $\times$ hispanica sampling sites.

\begin{tabular}{|c|c|c|c|c|c|}
\hline Location ID & Coordinates & Land-use Designation ${ }^{a}$ & $\begin{array}{c}\text { Distance to } \\
\text { nearest road }(\mathrm{m})\end{array}$ & $\begin{array}{l}\text { Average UFP } \\
\text { per } \mathbf{c m}^{3}\end{array}$ & $\begin{array}{l}\text { Average UFP } \\
\text { size (nm) }\end{array}$ \\
\hline Rural & $50.969 N-5.408 E$ & Mixed Forest & 400 & 3,689 & 79 \\
\hline Inner-city & $50.932 N-5.347 E$ & Discontinuous Urban Fabric & 5 & 14,451 & 72 \\
\hline Intersection & $50.930 \mathrm{~N}-5.360 \mathrm{E}$ & Discontinuous Urban Fabric & 5 & 14,208 & 65 \\
\hline
\end{tabular}

a Land-use Designation comes from the 2012 CORINE Land Cover database. 


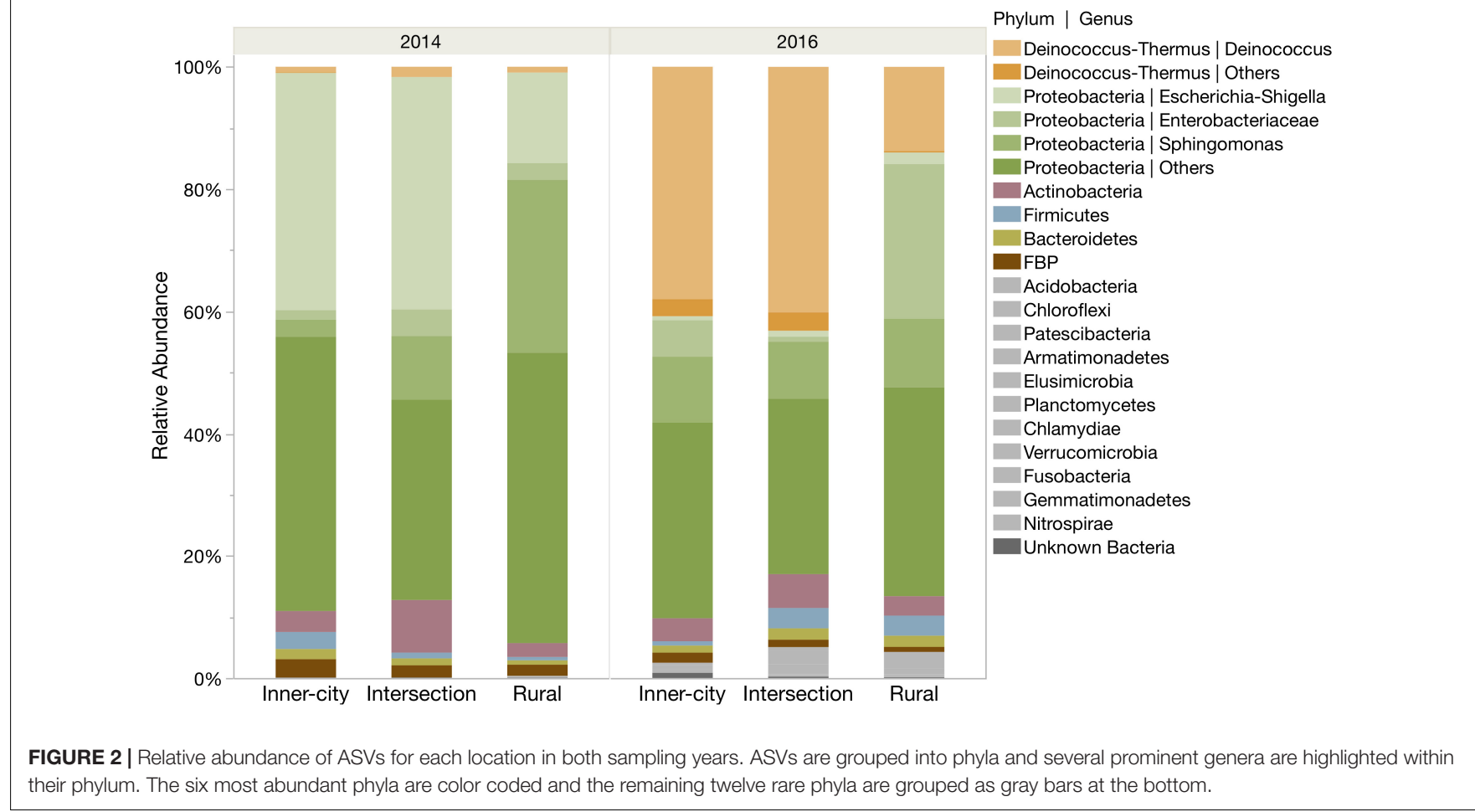

Phylum | Genus

their phylum. The six most abundant phyla are color coded and the remaining twelve rare phyla are grouped as gray bars at the bottom.

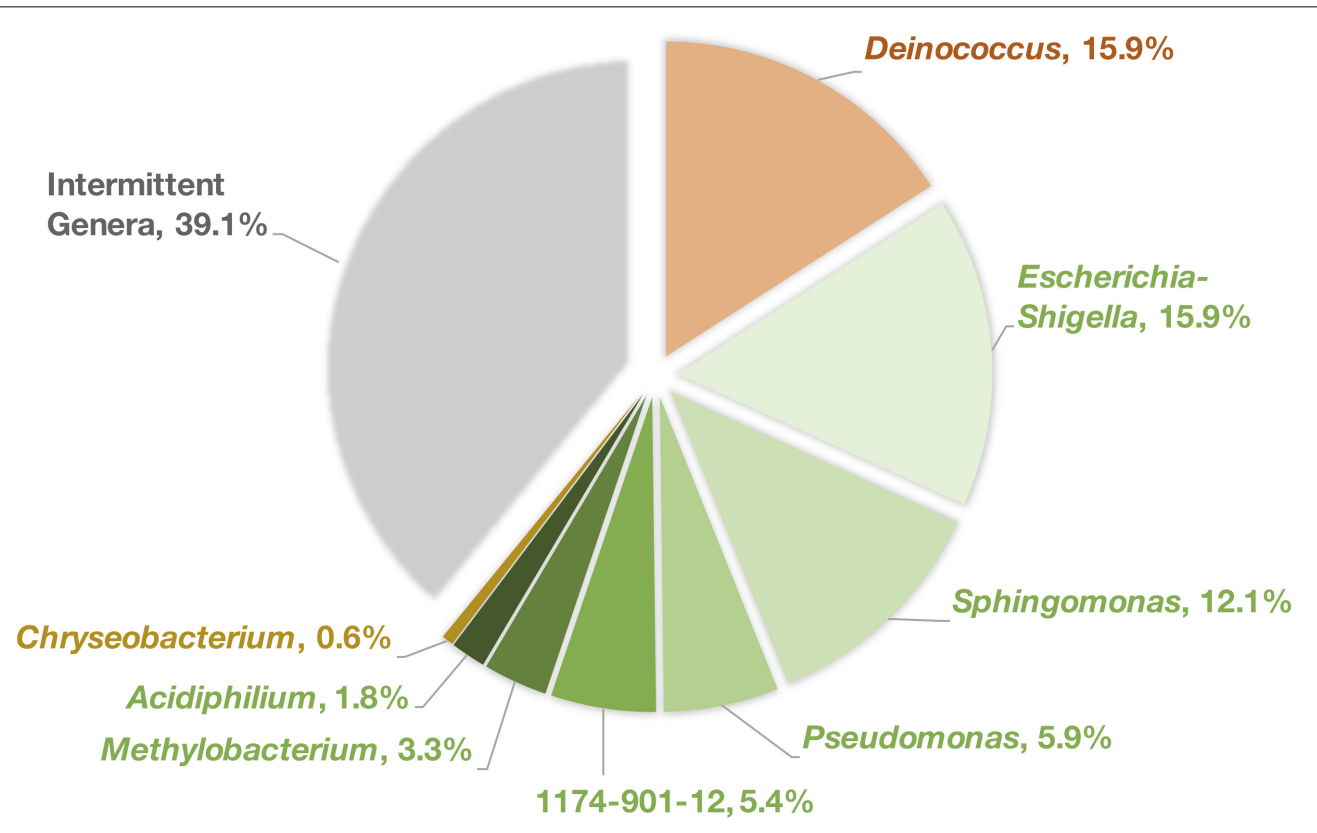

FIGURE 3 | Percentage of reads attributed to each of the shared persistent genera. Colors refer to the corresponding phylum for each genus, orange $=$ Deinococcus-Thermus, green = Proteobacteria, gold = Bacteroidetes, gray = all other intermittent bacterial genera .

To compare the different bacterial composition of each leaf phyllosphere by location and between years, a Bray-Curtis dissimilarity matrix was calculated for each sample. PCoA plotting (Figure 4) revealed that the communities are differentiated by year $(p=0.001)$, as seen on the first axis with $30.5 \%$ of the variation. Since most of the variation is explained by the first axis, we employed a blocking strategy to separate the years before testing for significance of community dissimilarity between tree locations $(p=0.001)$. Pairwise PERMANOVA analysis (Table 3) of the 2014 samples revealed the urban bacterial communities of inner-city and intersection were dissimilar $(p=0.032)$. But in 2016, the two urban communities 
TABLE 2 | Species and phylogenetic diversity measures of the Platanus $\times$ hispanica bacterial phyllosphere communities.

\begin{tabular}{|c|c|c|c|c|c|c|}
\hline & \multicolumn{3}{|c|}{2014} & \multicolumn{3}{|c|}{2016} \\
\hline & Rural & Inner-city & Intersection & Rural & Inner-city & Intersection \\
\hline Obs. ASVs & $79.0 \pm 6.2$ & $65.5 \pm 11.3$ & $72.5 \pm 6.1$ & $150.3 \pm 38.8$ & $111.5 \pm 15.6$ & $233.8 \pm 73.2$ \\
\hline Simpson & $0.966 \pm 0.001$ & $0.927 \pm 0.007$ & $0.945 \pm 0.014$ & $0.962 \pm 0.022$ & $0.962 \pm 0.009$ & $0.978 \pm 0.009$ \\
\hline Shannon & $5.59 \pm 0.06$ & $4.58 \pm 0.16$ & $5.25 \pm 0.25$ & $6.00 \pm 0.60$ & $5.79 \pm 0.13$ & $6.78 \pm 0.42$ \\
\hline Faith's PD & $7.59 \pm 0.79$ & $7.93 \pm 0.80$ & $8.13 \pm 0.34$ & $13.30 \pm 1.98$ & $11.44 \pm 1.26$ & $19.36 \pm 3.21$ \\
\hline
\end{tabular}

Mean \pm Standard Error, $n=4$.
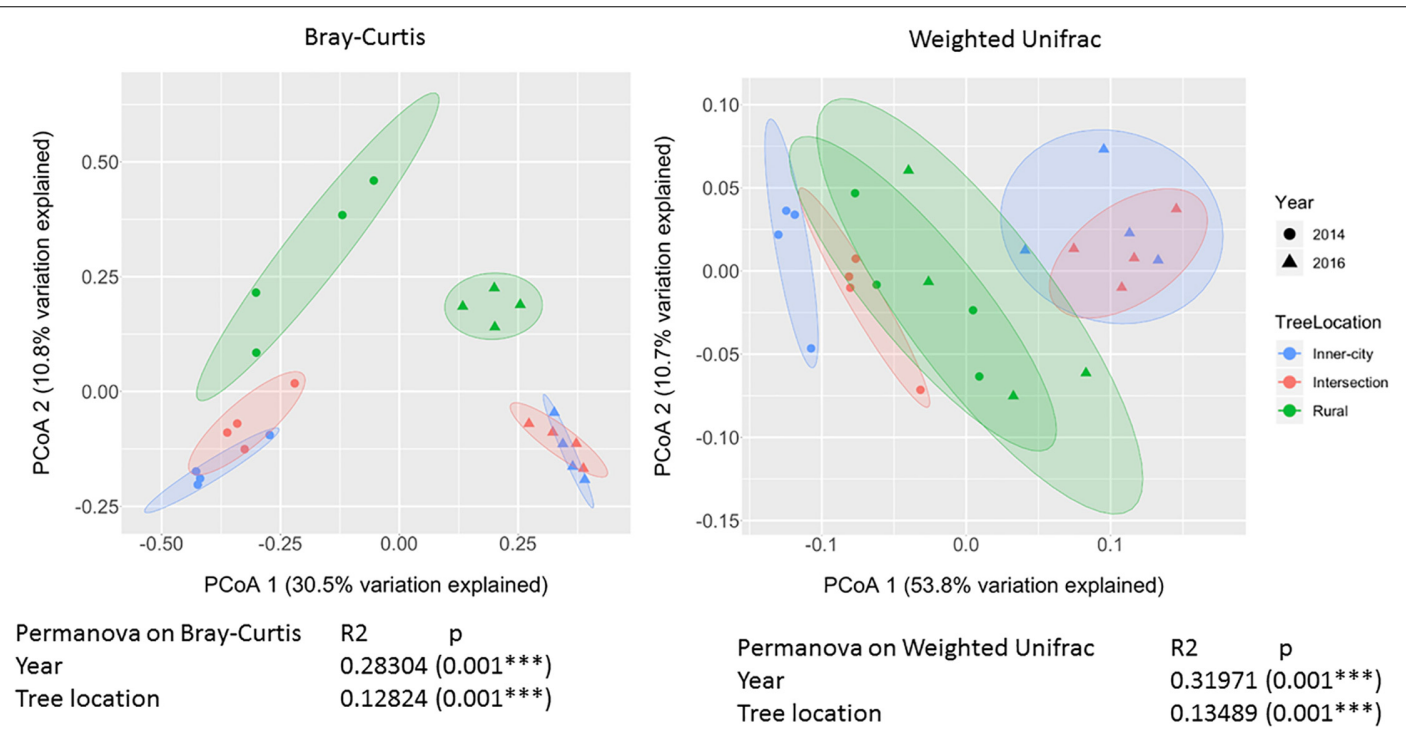

FIGURE 4 | PCOA plot of Bray-Curtis dissimilarity values and Weighted Unifrac between epiphytic bacterial communities on Platanus $\times$ hispanica leaves. Circles $=2014$, triangles $=2016$. Blue $=$ Inner-city, red $=$ Intersection, and green $=$ Rural. Each normal data ellipse is drawn at a level of 0.80 .

TABLE $3 \mid p$-value of each pairwise PERMANOVA (with FDR correction).

\begin{tabular}{lll}
\hline & $\mathbf{2 0 1 4}$ & $\mathbf{2 0 1 6}$ \\
\hline Intersection - Inner-city & 0.032 & 0.461 \\
Intersection - Rural & 0.032 & 0.045 \\
Rural - Inner-city & 0.032 & 0.045 \\
\hline
\end{tabular}

clustered together $(p=0.461)$. But what the urban leaves both had in common was that they were significantly different than the rural leaves in both sampling years $(2014, p=0.032$ and 2016, $p=0.045$ ).

\section{Linear Discriminant Analysis Effect Size Reveals Differential Abundance of Bacteria Between Land Class Types}

Controlling for difference between the years again, we were able to determine that land use class type had an effect on the relative abundance of two major bacterial classes in the phyllosphere. LDA inclusion threshold $>2.0, p<0.05$. The LEfSe cladogram of Figure 5 shows Actinobacteria and more specifically, Propionibacteriales, Propionibacteriaceae, and Friedmanniella, in addition to Flavobacteriaceae are more enriched on the urban leaves. Whereas Alphaproteobacteria, Methylocella, Sphingomonas, Acidobacteriales, Acidobacteriaceae Subgroup 1, and unknown Enterobacteriaceae are more enriched on leaves in the rural environment.

\section{Predicted Functional Profile for Epiphytic Bacteria}

Across all samples, 6,846 orthologs and 304 pathways were identified using the KEGG reference database. The similarity between predicted KEGG orthologs was visualized on a PCoA plot (Figure 6). Comparable to the Bray-Curtis dissimilarity of bacterial communities (Figure 4), the first axis differentiates between the years and the second axis distinguishes variation between the locations.

In order to determine how the functional profile of the microbiome may have changed over time, we compared the percentage of orthologs with significantly different abundances between 2014 and 2016 (Table 4). The rural tree remained relatively stable with $10.75 \%$ of the total orthologs changing between the years. In contrast, the inner-city and intersection trees were more dynamic; roughly half of the orthologs had significantly different abundances (Inner-city, 52.05\%; Intersection, $50.18 \%$ ). 


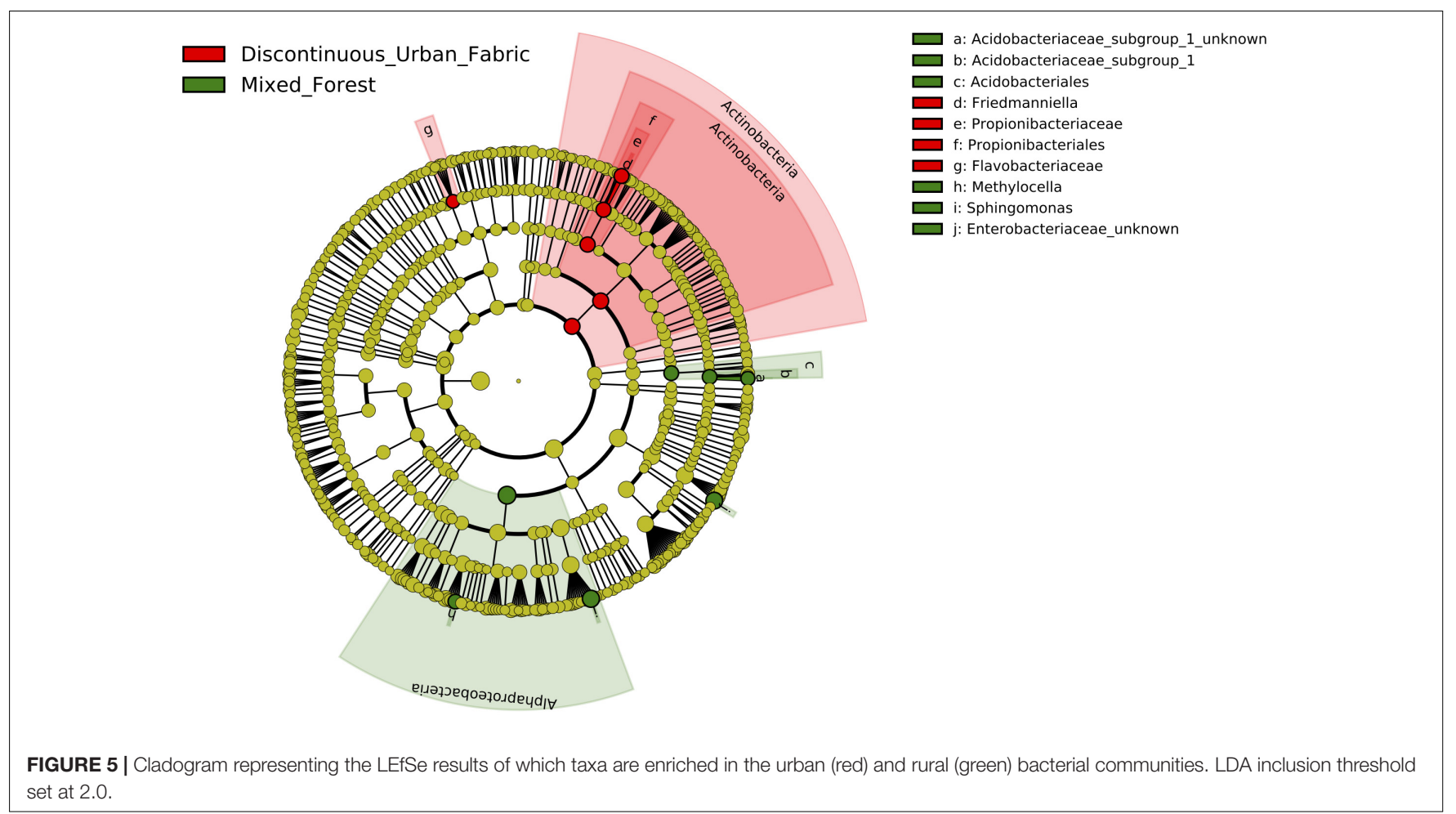

FIGURE 5 | Cladogram representing the LEfSe results of which taxa are enriched in the urban (red) and rural (green) bacterial communities. LDA inclusion threshold set at 2.0.

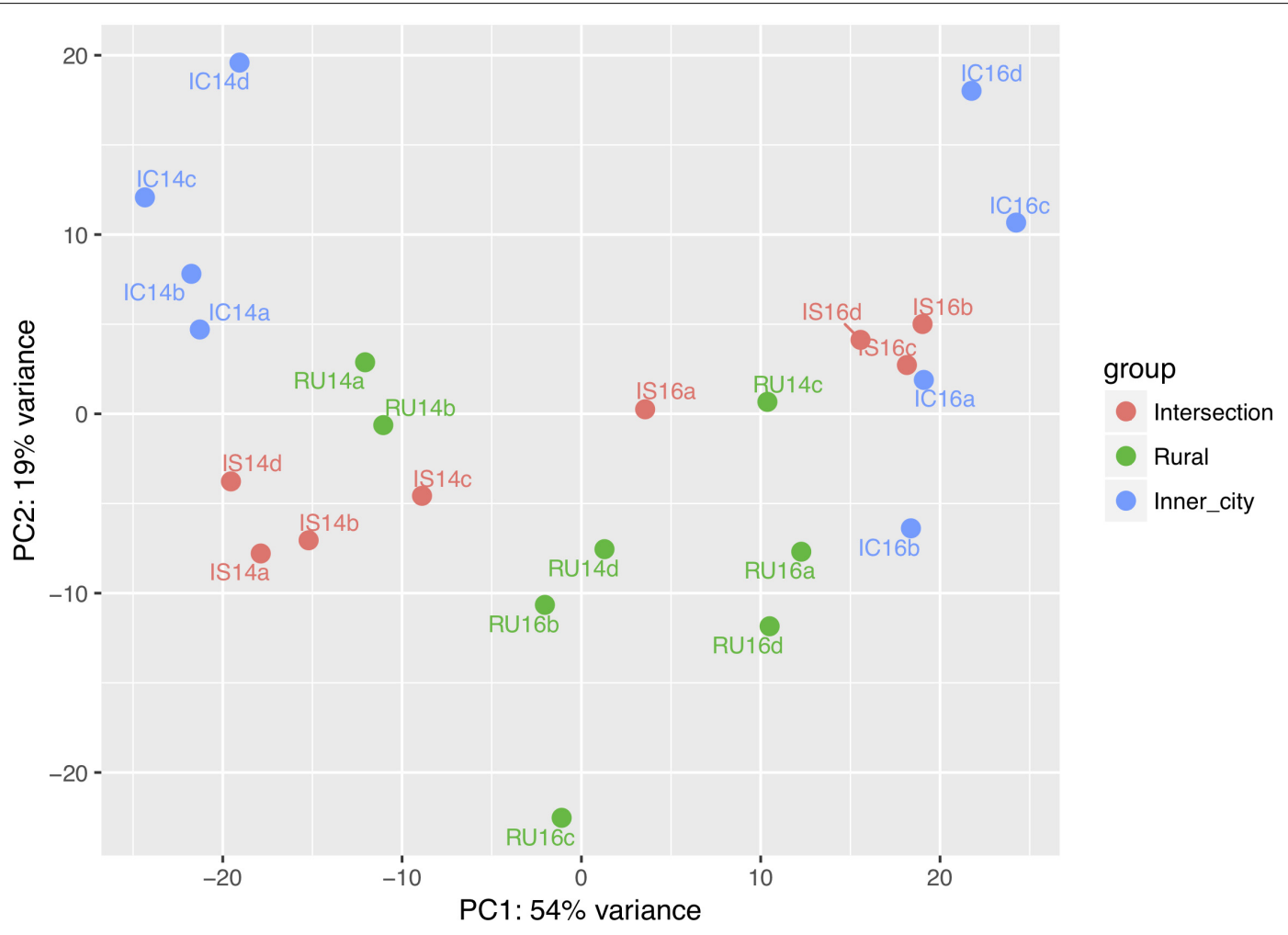

FIGURE 6 | PCoA plot for the similarity of predicted KEGG orthologs in each sample. IC = Inner-city, IS = Intersection, RU = Rural, $14=2014$ and $16=2016$. The lowercase letters refer to one of the four replicates from each group. 
TABLE 4 | Percentage of KEGG orthologs with significantly different abundances $(p<0.05)$ between years at each sampling location.

\begin{tabular}{lccc} 
& Inner-city & Intersection & Rural \\
\hline $2014-2016$ & $52.02 \%$ & $50.18 \%$ & $10.75 \%$ \\
\hline
\end{tabular}

To determine if the functional profile of the microbiome was influenced by location, we looked at the inferred orthologs within each year (Table 5). The percentage of orthologs with significantly different abundances was consistent between years for the inner-city and rural trees (2014, 21.22\%; 2016, 20.92\%). But their relationship to the intersection tree had more variation.

To determine if the urban phyllosphere might be metabolically enriched in alternative carbon sources, such as polycyclic aromatic hydrocarbons, we used the LEfSe tool to analyze the 154 KEGG annotated metabolic pathways predicted by Piphillin. The enriched pathways $(p<0.05)$ and corresponding LDA effect size scores for each land use class type are displayed in Figure 7. The bacteria on leaves in the mixed forest environment were more associated with pathways concerning "metabolism of cofactors and vitamins" and "glycan biosynthesis and metabolism," while the urban communities are predicted to contain more xenobiotics and lipid metabolism pathways.

\section{DISCUSSION}

In this study we used culture-independent methods to compare the epiphytic bacterial communities on Platanus $\times$ hispanica leaves between rural and urban locations to address what effects the local air quality might have on diversity, taxonomic composition, and potential functionality. As various studies of trees in tropical and temperate climates have shown, epiphytic bacterial communities are often more similar on trees of the same species than on other trees in the same location (Redford et al., 2010; Kim et al., 2012; Kembel et al., 2014; Laforest-lapointe et al., 2016). Therefore, we chose to study only Platanus $\times$ hispanica trees in a gradient of urbanization and traffic density and where global meteorological trends were similar. In addition, samples were taken from the same trees in two non-consecutive years to consider if a core group of shared bacteria would be present.

\section{Air Quality Characteristics}

From the perspective of microorganisms, the leaf habitat is vast in space but limited in nutrients and constantly exposed to environmental stresses like temperature fluctuations, UV radiation, and rainfall. In particular, leaf associated bacteria on trees in urban areas and close to roadways are recurrently

TABLE 5 | Percentage of KEGG orthologs with significantly different abundances $(p<0.05)$ between locations in each year of sampling.

\begin{tabular}{lcc}
\hline & $\mathbf{2 0 1 4}$ & $\mathbf{2 0 1 6}$ \\
\hline Intersection - Inner-city & $12.84 \%$ & $0.02 \%$ \\
Intersection - Rural & $10.99 \%$ & $17.00 \%$ \\
Rural - Inner-city & $21.22 \%$ & $20.92 \%$
\end{tabular}

exposed to aerosolized pollutants dispersed into the environment via vehicular exhaust (Weyens et al., 2015). As the majority of aerosolized particulate matter in urban environments is comprised of particles in the ultra-fine range of $100-10 \mathrm{~nm}$, we chose to focus on this fraction as well (Morawska et al., 1998; Junker et al., 2000). Our results indicate the average concentrations of particles measured in this study (Table 1) are similar to those published in other European studies of urban and residential areas (Matson, 2005; Puustinen et al., 2007; Pey et al., 2009; Hofman et al., 2016).

In addition, we also measured BC directly on the leaf surface. $\mathrm{BC}$ is a common component of PM and UFP formed during incomplete combustion and aerosolized in automobile exhaust. Recently, the BC fraction of particulate matter has come under greater scrutiny for its negative effects on human health and the environment (Janssen et al., 2012; De Prins et al., 2014). Zhu et al. (2002) reported that UFP and BC concentrations were both highest next to roadways, therefore we expected to find more $\mathrm{BC}$ on the urban leaves as a result of their increase exposure to UFP and close proximity to roads (Table 1). This was confirmed by our results of the higher number of BC particles (Figure 1A), on urban leaves as well as the greater percentage of leaf coverage by the BC particles (Figure 1B). Although the Intersection has more traffic passing by than the Inner-city location, it did not make a significant difference in average UFP counts or BC accumulation on leaves. The abundance of smaller UFP at both of the urban locations and especially the more residential Inner-city location, is of concern as this size fraction is associated with negative effects on respiratory health (Leitte et al., 2011; Li et al., 2016).

\section{Abundant Bacteria in the Platanus $\mathrm{x}$ hispanica Phyllosphere}

Proteobacteria, Actinobacteria, Firmicutes, and Bacteroidetes, that were the dominant phyla observed in our samples (Figure 2), are often reported in culture-dependent and culture-independent studies of leaf epiphytes. As expected, Proteobacteria was the dominant bacterial phylum in all samples, which is in accordance to numerous other studies on the bacterial community composition of plant leaves (Redford et al., 2010; Bodenhausen et al., 2013; Kembel et al., 2014; Laforest-lapointe et al., 2016; Lymperopoulou et al., 2016; Smets et al., 2016; Gandolfi et al., 2017). It has been suggested that this is due to the speed at which many bacteria within the Proteobacteria phylum replicate in comparison to other phyla (Leff et al., 2015).

Recently, bacteria within the phylum of DeinococcusThermus have also been described as typical phyllosphere residents (Redford et al., 2010; Laforest-lapointe et al., 2016). This might be due to a change in the methodology for studying aerial sections of the plant. Clone libraries and amplicon strategies not including the 799F primer for chloroplast exclusion (Chelius and Triplett, 2001) seem to be biased against this phylum (Redford and Fierer, 2009; Jackson and Denney, 2011; Beckers et al., 2016; Gandolfi et al., 2017). Indeed, the use of 799F-1115R primers found Deinococcus-Thermus on leaves of nearly all the 56 of the tree species studied (Redford et al., 2010). 




FIGURE 7 | LDA scores of the metabolic pathways enriched in the urban (red) and rural (green) epiphytic phyllosphere bacterial communities. Inclusion threshold set at an LDA score of 2.5 .

Only two Deinococcus-Thermus genera, Deinococcus and Truepera, were identified in our samples. Of these, Deinococcus was more abundant on all leaves and in both years. This is not surprising as Deinococcus species are reportedly highly resistant to UV radiation and desiccation, which are fairly common environmental stressors to the phyllosphere. There are indications that Deinococcus might be useful for degradation of aromatic compounds. Deinococcus bacteria capable of phenanthrene degradation has been isolated from Ixora leaves in Thailand (Waight et al., 2007).

Similar to Deinococcus-Thermus, the candidate phylum FBP is also associated with extreme environments and often found in 16S rRNA gene sequencing of phyllosphere samples (Laforest-lapointe et al., 2016; Ruiz-Pérez et al., 2016). However, not much is known about these candidate bacteria since only one has been successfully cultured and studied (Tahon et al., 2018).

\section{Persistent Core Microbiome}

Despite the dynamic and complex nature of host-associated microbiomes, it has been theorized that a core portion of each community is persistent across time and habitats (Shade and Handelsman, 2012). Members of the core microbiome are credited with being an integral part for the optimal microbial functioning needed to promote the health of their hostspecies (Toju et al., 2018).
In this study, we identified which genera were persistently found at each location and then compared these to find the shared persistent bacteria. We chose to compare genera rather than ASVs in order to include the possibility of functional redundancy within the same genus. As deciduous trees grow new leaves every year and the order of bacterial colonization matters (Maignien et al., 2014), it may not be reasonable to expect the same ASVs but to consider that ASVs of the same phylogenetic lineage will share the desired functional trait.

Although it is likely that the eight shared genera (Figure 3) are connected to the core microbiome because they were detected the leaf bacterial community in two non-consecutive years, due to sampling limitations, it is still unknown if they are universal to all Platanus trees or they are localized to this region and climate. Only one other study has sought to evaluate the taxonomic composition of bacterial communities on Platanus leaves (Gandolfi et al., 2017) for which we can compare our results. Out of the eight genera identified in our study, only Sphingomonas, Pseudomonas, and Methylobacterium were also consistently identified on Platanus $\times$ acerifolia leaves in Milan (Italy) over one growing season. Therefore, these three genera stand out as the most probable members for the core microbiome of Platanus leaves. It should be noted that Platanus $\times$ acerifolia and Platanus $\times$ hispanica are historically synonymous names for the same tree (Besnard et al., 2002) and bacterial communities on leaves of the two other 
common Platanus species, orientalis and occidentalis, have not yet been reported.

\section{Intra-Tree and Inter-Tree Diversity}

The decrease in available green space in cities is often associated with negative effects on human health, mostly related to mental and physical wellbeing (Jim et al., 2018). In addition to the benefits received from eukaryotic diversity, exposure to a variety of prokaryotes is connected with establishing and maintaining a healthy immune system (Haahtela et al., 2013; Rook, 2013). We clearly see that the built environment limits plant and animal biodiversity in cities, so there is concern regarding the loss of microbial richness, which is more difficult to assess.

Phyllospheric communities frequently undergo disturbances such as changes in UV radiation, precipitation, and resource availability that disrupt the natural community succession (Redford and Fierer, 2009). The significant temporal difference in intra-tree diversity between 2014 and 2016 is likely to be a combination of multiple environmental factors. Therefore, within each year we sampled from the same trees located in close proximity to each other so meteorological changes would have less of an effect on location. Based on a comparison with the leaves of the trees in the urban and rural areas, our results indicated that the richness and diversity of bacteria on urban Platanus $\times$ hispanica tree leaves are not significantly impacted by increased exposure to UFP and BC (Table 2). This fits with other similar studies on urban phyllospheric bacterial diversity (Smets et al., 2016; Laforest-Lapointe et al., 2017).

Redford and Fierer (2009), Laforest-lapointe et al. (2016), and Gandolfi et al. (2017) all found that over one growing season, the influence of site was a stronger driver of inter-tree compositional diversity for the phyllosphere than temporal changes. We chose to study a longer separation of time, where the trees have lost and regained their leaves twice, to address the impact of site on the establishment of new bacterial communities rather than its effect on the community succession.

Our results indicate that the taxonomic composition of epiphytic bacterial communities is influenced by urbanization. It was apparent that each community saw a large temporal shift in bacterial taxa, but within each year the general relationships between communities remained nearly the same (Figure 4).

\section{Differential Abundant Genera Between Locations}

Consistent in both sampling years, the urban trees shared a similar percentage of the same dominant genus (Figure 2). In 2014, this was Escherichia-Shigella and in 2016, it changed to be Deinococcus. Interestingly, when considering changes in relative abundance at the urban trees, Deinococcus was infrequently identified in 2014 and Escherichia-Shigella was, in turn, similarly, scarce in 2016. The rural tree had a distinctly different pattern of abundant bacteria compared to the urban trees in both sampling years.

The bacteria revealed by LEfSe analysis to be enriched at the urban and rural locations in both years are mostly those that are typically found in environmental samples (Figure 5). The abundance of Propionibacteriaceae on the urban leaves stands out however, as this family is often associated with human skin. Lehtimäki et al. (2017) found Friedmaniella was enriched on the forearms of children living in urban areas compared to those in rural homes. Also of note is that although the Sphingomonas genus was persistently identified on all Platanus $\times$ hispanica leaves (Figure 3), it was shown here to be more commonly identified in the rural samples.

\section{Functional Profiles}

We wanted to know if the temporal and spatial differences in taxonomic composition (Figure 4) would also be reflected in the inferred functional composition (Figure 6). For this purpose, we employed Piphillin because it has the flexibility to interpret inferences from ASV tables rather than needing a closed reference OTU picking strategy. One of the unfortunate disadvantages is that Piphillin is less accurate than PICRUSt and Tax4fun when used on environmental samples (Iwai et al., 2016). Hopefully this will change in the future when more genomes of environmental microbes are fully sequenced and added to databases. It is also important to note, that although the functional orthologs and pathways are directly inferred from the taxonomic composition of each bacterial community, Piphillin uses a reference database to correct for variation in $16 \mathrm{~S}$ copy number and therefore the functional differential abundance cannot be directly compared to the taxonomic differential abundance.

The KEGG orthologs predicted for 2014 were compared to those predicted for 2016 at each location in order to bring a greater understanding of how the functional aspect of each bacterial community changed over time (Table 4). The urban trees saw a larger change in ortholog composition between the sampling years than the rural tree. This suggests that even though the taxonomic composition of the rural tree was significantly different, the predicted functional profile of the bacteria remained similar.

The difference in ortholog composition between locations (Table 5) also mirrors the differences seen in taxonomic compositions. In both sampling years, roughly $21 \%$ of the rural and inner-city orthologs had significantly different abundances. However, the dissimilarity between each of those bacterial communities to the intersection community was more dynamic across both years. In terms of geographic distance, rural and inner-city are also further away from each other and experiencing other environmental conditions (neighboring plants versus more artificial city surfaces), so a higher percentage of differently expressed KEGG orthologs suggest that the communities exert different metabolic functions. In order to confirm this, a shotgun sequencing approach, metabolomics study or individual-based microbial ecology (IBME) should be performed to quantify the performance of microorganisms in their natural habitats. An IBME approach has confirmed that heterogeneity in fructose availability has an important role in the reproductive success of bacterial immigrants to the leaf surface (Remus-Emsermann and Leveau, 2010). How atmospheric car-exhaust related air pollutants might affect carbon substrates in the phyllosphere and therefore sustain metabolically different microbial communities remains to be explored. 
We limited the LEfSe analysis (Figure 7) to include only the metabolic pathways as our interest was mainly in determining if the urban trees had a greater inclination toward accumulating bacteria with pathways to degrade common traffic related compounds, such as polycyclic aromatic hydrocarbons. While many of these were not directly enriched, LEfSe did reveal that overall degradation of xenobiotic compounds was predicted to be more common in the urban phyllosphere bacterial communities.

The benzoate degradation pathway is also enriched in the urban samples. This pathway is intimately involved with the degradation of monoaromatic hydrocarbons such as benzene and toluene, as well as degradation of polycyclic aromatic hydrocarbons metabolites. Although these results do not necessarily mean that the enzymes in this pathway are more active in the urban bacterial communities. It has been observed previously that bacteria with hydrocarbon degradation potential are inhabiting the phyllosphere of city plants, e.g., we isolated previously hydrocarbonoclastic Rhodococcus (Stevens et al., 2017b) and Bacillus (Stevens et al., 2017a) on Hedera helix leaves.

\section{CONCLUSION}

The results of our biennial study on urban and rural leaf-associated epiphytic bacterial communities provide additional insights in the phyllosphere microbiome of Platanus $\times$ hispanica trees in the city. Bacterial communities on urban leaves are exposed to a greater concentration of harmful aerosolized pollutants from traffic exhaust compared to rural leaves. Urbanization alone was not a major factor explaining bacterial diversity in the phyllosphere and this is in line with previous studies on Platanus suggesting that seasonality acted as a stronger driver of alkane hydroxylase genes involved in the degradation of atmospheric hydrocarbons, rather than sampling location. Although we found large differences between the two sampling years, we consistently observed that human associated bacteria and degradation pathways for xenobiotic compounds are more likely to be enriched in the urban samples.

Because we performed a biennial study of the Platanus microbiome, we could determine that the patterns of dissimilarity in taxonomic composition between the sites were somewhat

\section{REFERENCES}

European Union (2018). Copernicus Land Monitoring Service 2018. Copenhagen: European Environment Agency.

Afgan, E., Baker, D., Batut, B., Van Den Beek, M., Bouvier, D., Ech, M., et al. (2018). The Galaxy platform for accessible, reproducible and collaborative biomedical analyses: 2018 update. Nucleic Acids Res. 46, W537-W544. doi: 10.1093/nar/gky379

Afzal, M., Khan, Q. M., and Sessitsch, A. (2014). Endophytic bacteria: prospects and applications for the phytoremediation of organic pollutants. Chemosphere 117, 232-242. doi: 10.1016/j.chemosphere.2014. 06.078

Barac, T., Taghavi, S., Borremans, B., Provoost, A., Oeyen, L., Colpaert, J. V., et al. (2004). Engineered endophytic bacteria improve phytoremediation of watersoluble, volatile, organic pollutants. Nat. Biotechnol. 22, 583-588. doi: 10.1038/ nbt960 predictable. It also appears the taxonomic composition is dependent on more environmental factors than just the surrounding land use class designation.

Our study quantified part of the multi-complex effects of urbanization and associated air pollution on the Platanus phyllospheric microbiomes in Hasselt (Belgium) and how this may subsequently impact the health of urban inhabitants. Further research into the influence of urban microbiomes is certainly needed. Information on the temporal, geographical and functional variations, will improve our understanding of plant-microbe interactions and how we can manipulate these communities in future to scavenge air-borne pollutants in the city.

\section{DATA AVAILABILITY}

The datasets generated for this study can be found in SRA NCBI, PRJNA505409.

\section{AUTHOR CONTRIBUTIONS}

JE and NW conceived the study design. JV, NW, and ST coordinated the execution of the project by JE. JE wrote this manuscript in collaboration with ST. HB performed the black carbon measurements on the leaves. JV promoted the study. All authors contributed to the elaboration of the study design and took part in reviewing the methods read and approved the final version of the manuscript.

\section{FUNDING}

This work was supported by Grant G0D0916N from FWOFlanders, Belgium, the Methusalem project 08M03VGRJ.

\section{ACKNOWLEDGMENTS}

We thank the city of Hasselt and the staff at Domein Bokrijk for granting access for the sampling.

Beckers, B., Op De Beeck, M., Thijs, S., Truyens, S., Weyens, N., Boerjan, W., et al. (2016). Performance of 16s rDNA primer pairs in the study of rhizosphere and endosphere bacterial microbiomes in metabarcoding studies. Front. Microbiol. 7:650. doi: 10.3389/fmicb.2016.00650

Berg, G., Mahnert, A., and Moissl-Eichinger, C. (2014). Beneficial effects of plant-associated microbes on indoor microbiomes and human health? Front. Microbiol. 5:15. doi: 10.3389/fmicb.2014.00015

Besnard, G., Tagmount, A., Baradat, P., Vigouroux, A., and André, B. (2002). Molecular approach of genetic affinities between wild and ornamental Platanus. Euphytica 126, 401-412. doi: 10.1023/A:101991242 5987

Bodenhausen, N., Horton, M. W., and Bergelson, J. (2013). Bacterial communities associated with the leaves and the roots of Arabidopsis thaliana. PLoS One 8:e56329. doi: 10.1371/journal.pone.0056329

Bové, H., Steuwe, C., Fron, E., Slenders, E., D’Haen, J., Fujita, Y., et al. (2016). Biocompatible label-free detection of carbon black particles by femtosecond 
pulsed laser microscopy. Nano Lett. 16, 3173-3178. doi: 10.1021/acs.nanolett. $6 \mathrm{~b} 00502$

Callahan, B. J., McMurdie, P. J., Rosen, M. J., Han, A. W., Johnson, A. J. A., and Holmes, S. P. (2016). DADA2: high-resolution sample inference from Illumina amplicon data. Nat. Methods 13, 581-583. doi: 10.1038/nmeth.3869

Chelius, M. K., and Triplett, E. W. (2001). The diversity of archaea and bacteria in association with the roots of Zea mays L. Microb. Ecol. 41, 252-263. doi: $10.1007 / \mathrm{s} 002480000087$

Coretti, L., Cristiano, C., Florio, E., Scala, G., Lama, A., Keller, S., et al. (2017). Sexrelated alterations of gut microbiota composition in the BTBR mouse model of autism spectrum disorder. Sci. Rep. 7:45356. doi: 10.1038/srep45356

De Prins, S., Dons, E., Van Poppel, M., Int Panis, L., Van de Mieroop, E., Nelen, V., et al. (2014). Airway oxidative stress and inflammation markers in exhaled breath from children are linked with exposure to black carbon. Environ. Int. 73, 440-446. doi: 10.1016/j.envint.2014.06.017

Gandolfi, I., Canedoli, C., Imperato, V., Tagliaferri, I., Gkorezis, P., Vangronsveld, J., et al. (2017). Diversity and hydrocarbon-degrading potential of epiphytic microbial communities on Platanus $\times$ acerifolia leaves in an urban area. Environ. Pollut. 220, 650-658. doi: 10.1016/j.envpol.2016.10.022

Gregory Caporaso, J., Kuczynski, J., Stombaugh, J., Bittinger, K., Bushman, F. D., Costello, E. K., et al. (2010). correspondence QIIME allows analysis of highthroughput community sequencing data Intensity normalization improves color calling in SOLiD sequencing. Nat. Methods 7, 335-336. doi: 10.1038/ nmeth0510-335

Haahtela, T., Holgate, S., Pawankar, R., Akdis, C. A., Benjaponpitak, S., Caraballo, L., et al. (2013). The biodiversity hypothesis and allergic disease: world allergy organization position statement. World Allergy Organ. J. 6:3. doi: 10.1186/1939-4551-6-3

Hervé, M. (2018). RVAideMemoire: Testing and Plotting Procedures for Biostatistics. Available at: https://cran.r-project.org/package=RVAideMemoire (accessed October 12, 2018)

Hofman, J., Staelens, J., Cordell, R., Stroobants, C., Zikova, N., Hama, S. M. L., et al. (2016). Ultrafine particles in four European urban environments: results from a new continuous long-term monitoring network. Atmos. Environ. 136, 68-81. doi: 10.1016/j.atmosenv.2016.04.010

Holman, C., Harrison, R., and Querol, X. (2015). Review of the efficacy of low emission zones to improve urban air quality in European cities. Atmos. Environ. 111, 161-169. doi: 10.1016/j.atmosenv.2015.04.009

Iwai, S., Weinmaier, T., Schmidt, B. L., Albertson, D. G., Poloso, N. J., Dabbagh, K., et al. (2016). Piphillin: improved prediction of metagenomic content by direct inference from human microbiomes. PLoS One 11:e0166104. doi: 10.1371/ journal.pone.0166104

Jackson, C. R., and Denney, W. C. (2011). Annual and seasonal variation in the phyllosphere bacterial community associated with leaves of the Southern Magnolia (Magnolia grandiflora). Microb. Ecol. 61, 113-122. doi: 10.1007/ s00248-010-9742-2

Janssen, B. G., Madhloum, N., Gyselaers, W., Bijnens, E., Clemente, D. B., Cox, B., et al. (2017). Cohort profile: the ENVIRonmental influence ON early AGEing (ENVIR ON AGE): a birth cohort study. Int. J. Epidemiol. 46, 1386m-1387m. doi: 10.1093/ije/dyw269

Janssen, N. A., Gerlofs-Nijland, M. E., Lanki, T., Salonen, R. O., Cassee, F., Hoek, G., et al. (2012). Health Effects of Black Carbon. Copenhagen: World Health Organization Regional Office for Europe.

Jim, C. Y., Konijnendijk van den Bosch, C., and Chen, W. Y. (2018). Acute challenges and solutions for urban forestry in compact and densifying cities. J. Urban Plan. Dev. 144:04018025. doi: 10.1061/(ASCE)UP.1943-5444. 0000466

Junker, M., Kasper, M., Röösli, M., Camenzind, M., Künzli, N., Monn, C., et al. (2000). Airborne particle number profiles, particle mass distributions and particle-bound $\mathrm{PAH}$ concentrations within the city environment of Basel: an assessment as part of the BRISKA Project. Atmos. Environ. 34, 3171-3181. doi: 10.1016/S1352-2310(99)00372-6

Kembel, S. W., Connor, T. K. O., Arnold, H. K., Hubbell, S. P., and Wright, S. J. (2014). Relationships between phyllosphere bacterial communities and plant functional traits in a neotropical forest. PNAS 111, 13715-13720. doi: 10.1073/ pnas. 1216057111

Kim, M., Singh, D., Lai-Hoe, A., Go, R., Rahim, R. A., Ainuddin, A. N., et al. (2012). Distinctive phyllosphere bacterial communities in tropical trees. Microb. Ecol. 63, 674-681. doi: 10.1007/s00248-0119953-1

King, G. M. (2014). Urban microbiomes and urban ecology: how do microbes in the built environment affect human sustainability in cities? J. Microbiol. 52, 721-728. doi: 10.1007/s12275-014-4364-x

Laforest-lapointe, I., Messier, C., and Kembel, S. W. (2016). Host species identity, site and time drive temperate tree phyllosphere bacterial community structure. Microbiome 4:27. doi: 10.1186/s40168-016-0174-1

Laforest-Lapointe, I., Messier, C., and Kembel, S. W. (2017). Tree leaf bacterial community structure and diversity differ along a gradient of urban intensity. mSystems 2:e0087-17. doi: 10.1128/mSystems.00087-17

Leff, J. W., Del Tredici, P., Friedman, W. E., and Fierer, N. (2015). Spatial structuring of bacterial communities within individual Ginkgo biloba trees. Environ. Microbiol. 17, 2352-2361. doi: 10.1111/1462-2920.12695

Lehtimäki, J., Karkman, A., Laatikainen, T., Paalanen, L., Von Hertzen, L., Haahtela, T., et al. (2017). Patterns in the skin microbiota differ in children and teenagers between rural and urban environments. Sci. Rep. 7:45651. doi: 10.1038/srep45651

Leitte, A. M., Schlink, U., Herbarth, O., Wiedensohler, A., Pan, X. C., Hu, M., et al. (2011). Size-segregated particle number concentrations and respiratory emergency room visits in Beijing, China. Environ. Health Perspect. 119, 508513. doi: 10.1289/ehp.1002203

Leung, M. H. Y., Tong, X., Tong, J. C. K., and Lee, P. K. H. (2018). Airborne bacterial assemblage in a zero carbon building: a case study. Indoor Air 28, 40-50. doi: 10.1111/ina.12410

Li, N., Georas, S., Alexis, N., Fritz, P., Xia, T., Williams, M. A., et al. (2016). A work group report on ultrafine particles (American Academy of Allergy, Asthma \& Immunology): Why ambient ultrafine and engineered nanoparticles should receive special attention for possible adverse health outcomes in human subjects. J. Allergy Clin. Immunol. 138, 386-396. doi: 10.1016/j.jaci.2016. 02.023

Love, M. I., Huber, W., and Anders, S. (2014). Moderated estimation of fold change and dispersion for RNA-seq data with DESeq2. Genome Biol. 15:550. doi: 10.1186/s13059-014-0550-8

Lymperopoulou, D. S., Adams, R. I., and Lindow, S. E. (2016). Contribution of vegetation to the microbial composition of nearby outdoor air. Appl. Environ. Microbiol. 82, 3822-3833. doi: 10.1128/AEM.00610-16

Maignien, L., DeForce, E. A., Chafee, M. E., Eren, A. M., and Simmons, S. L. (2014). Ecological succession and stochastic variation in the assembly of Arabidopsis thaliana phyllosphere communities. mBio 5:e0682-13. doi: 10.1128/mBio. 00682-13

Matson, U. (2005). Indoor and outdoor concentrations of ultrafine particles in some Scandinavian rural and urban areas. Sci. Total Environ. 343, 169-176. doi: 10.1016/j.scitotenv.2004.10.002

McMurdie, P. J., and Holmes, S. (2014). Waste not, want not: why rarefying microbiome data is inadmissible. PLoS Comput. Biol. 10:e1003531. doi: 10.1371/ journal.pcbi.1003531

Miletto, M., and Lindow, S. E. (2015). Relative and contextual contribution of different sources to the composition and abundance of indoor air bacteria in residences. Microbiome 3:61. doi: 10.1186/s40168-015-0128-z

Morawska, L., Thomas, S., Bofinger, N., Wainwright, D., and Neale, D. (1998). Comprehensive characterization of aerosols in a subtropical urban atmosphere: particle size distribution and correlation with gaseous pollutants. Atmos. Environ. 32, 2467-2478.

Nowak, D. J., Hirabayashi, S., Bodine, A., and Hoehn, R. (2013). Modeled PM2.5 removal by trees in ten U.S. cities and associated healtheffects. Environ. Pollut. 178, 395-402. doi: 10.1016/j.envpol.2013.03.050

Oksanen, J. (2015). Multivariate analysis of ecological communities in R: vegan tutorial. $R$ Doc. 43, 11-12. doi: 10.1016/0169-5347(88)90124-3

Paradis, E., Claude, J., and Strimmer, K. (2004). APE: analyses of phylogenetics and evolution in R language. Bioinformatics 20, 289-290. doi: 10.1093/ bioinformatics/btg412

Pey, J., Querol, X., Alastuey, A., Rodríguez, S., Putaud, J. P., and Van Dingenen, R. (2009). Source apportionment of urban fine and ultra-fine particle number concentration in a Western Mediterranean city. Atmos. Environ. 43, 4407-4415. doi: 10.1016/j.atmosenv.2009.05.024

Popek, R., Gawrońska, H., Wrochna, M., Gawronski, S., and Saebø, A. (2013). Particulate matter on foliage of 13 woody species: deposition on surfaces 
and phytostabilisation in waxes - a 3-year study. Int. J. Phytoremediat. 15, 245-256.

Price, M. N., Dehal, P. S., and Arkin, A. P. (2010). FastTree 2 - approximately maximum-likelihood trees for large alignments. PLoS One 5:e9490. doi: 10. 1371/journal.pone.0009490

Puustinen, A., Hämeri, K., Pekkanen, J., Kulmala, M., de Hartog, J., Meliefste, K., et al. (2007). Spatial variation of particle number and mass over four European cities. Atmos. Environ. 41, 6622-6636. doi: 10.1016/j.atmosenv.2007. 04.020

Quast, C., Pruesse, E., Yilmaz, P., Gerken, J., Schweer, T., Yarza, P., et al. (2013). The SILVA ribosomal RNA gene database project: improved data processing and web-based tools. Nucleic Acids Res. 41, 590-596. doi: 10.1093/nar/gks1219

R Development Core Team (2018). R: A Language and Environment for Statistical Computing. Vienna: R Foundation for Statistical Computing.

Redford, A. J., Bowers, R. M., Knight, R., Linhart, Y., and Fierer, N. (2010). The ecology of the phyllosphere: geographic and phylogenetic variability in the distribution of bacteria on tree leaves. Environ. Microniol. 12, 2885-2893. doi: $10.1111 / \mathrm{j} .1462-2920.2010 .02258 . \mathrm{x}$

Redford, A. J., and Fierer, N. (2009). Bacterial succession on the leaf surface: a novel system for studying successional dynamics. Microb. Ecol. 58, 189-198.

Remus-Emsermann, M. N., and Leveau, J. H. (2010). Linking environmental heterogeneity and reproductive success at single-cell resolution. ISME J. 4, 215-222. doi: 10.1038/ismej.2009.110

Rook, G. A. (2013). Regulation of the immune system by biodiversity from the natural environment: an ecosystem service essential to health. Proc. Natl. Acad. Sci. U.S.A. 110, 18360-18367. doi: 10.1073/pnas.1313731110

Ruiz-Pérez, C. A., Restrepo, S., and Zambrano, M. M. (2016). Microbial and functional diversity within the phyllosphere of Espeletia species in an Andean high-mountain ecosystem. Appl. Environ. Microbiol. 82, 1807-1817. doi: 10. 1128/aem.02781-15

Saleem, M., Meckes, N., Pervaiz, Z. H., and Traw, M. B. (2017). Microbial interactions in the phyllosphere increase plant performance under herbivore biotic stress. Front. Microbiol. 8:41. doi: 10.3389/fmicb.2017.00041

Segata, N., Izard, J., Waldron, L., Gevers, D., Miropolsky, L., Garrett, W. S., et al. (2011). Metagenomic biomarker discovery and explanation. Genome Biol. 12:R60. doi: 10.1186/gb-2011-12-6-r60

Shade, A., and Handelsman, J. (2012). Beyond the Venn diagram: the hunt for a core microbiome. Environ. Microbiol. 14, 4-12. doi: 10.1111/j.1462-2920.2011. 02585.x

Smets, W., Wuyts, K., Oerlemans, E., Wuyts, S., Denys, S., Samson, R., et al. (2016). Impact of urban land use on the bacterial phyllosphere of ivy (Hedera sp.). Atmos. Environ. 147, 376-383. doi: 10.1016/j.atmosenv.2016.10.017

Stevens, V., Thijs, S., McAmmond, B., Langill, T., Van Hamme, J., Weyens, N., et al. (2017a). Draft genome sequence of Bacillus licheniformis VSD4, a diesel fuel-degrading and plant growth-promoting phyllospheric bacterium. Genome Announc. 5:e00027-17. doi: 10.1128/genomeA.00027-17

Stevens, V., Thijs, S., McAmmond, B., Langill, T., Van Hamme, J., Weyens, N., et al. (2017b). Draft genome sequence of Rhodococcus erythropolis VSD3, a diesel fuel-degrading and plant growth-promoting bacterium isolated from Hedera helix leaves. Genome Announc. 5:e01680-16. doi: 10.1128/genomeA.01680-16

Sæbø, A., Popek, R., Nawrot, B., Hanslin, H. M., Gawronska, H., and Gawronski, S. W. (2012). Plant species differences in particulate matter accumulation on leaf surfaces. Sci. Total Environ. 427-428, 347-354. doi: 10.1016/j.scitotenv.2012. 03.084

Taghavi, S., Barac, T., Greenberg, B., Vangronsveld, J., Van Der Lelie, D., and Borremans, B. (2005). Horizontal gene transfer to endogenous endophytic bacteria from poplar improves phytoremediation of toluene horizontal gene transfer to endogenous endophytic bacteria from poplar improves phytoremediation of toluene. Appl. Environ. Microbiol. 71, 8500-8505. doi: 10.1128/AEM.71.12.8500

Tahon, G., Tytgat, B., Lebbe, L., Carlier, A., and Willems, A. (2018). Abditibacterium utsteinense sp. nov., the first cultivated member of candidate phylum FBP, isolated from ice-free Antarctic soil samples. Syst. Appl. Microbiol. 41, 279-290. doi: 10.1016/j.syapm.2018.01.009

The Guardian (2017). More Than 100 Chinese Cities Now Above 1 Million People. London: The Guardian.

Toju, H., Peay, K. G., Yamamichi, M., Narisawa, K., Hiruma, K., Naito, K., et al. (2018). Core microbiomes for sustainable agroecosystems. Nat. Plants 4, 247-257. doi: 10.1038/s41477-018-0139-4

United Nations (2018). World Urbanization Prospects: The 2018 Revision, Key Facts. 2. New York, NY: United Nations.

Vorholt, J. A., (2012). Microbial life in the phyllosphere. Nat. Rev. Microbiol. 10, 828-840. doi: 10.1038/nrmicro2910

Waight, K., Pinyakong, O., and Luepromchai, E. (2007). Degradation of phenanthrene on plant leaves by phyllosphere bacteria. J. Gen. Appl. Microbiol. 53, 265-272. Available at: http://www.ncbi.nlm.nih.gov/pubmed/18057816

Walker, J. J., and Pace, N. R. (2007). Phylogenetic composition of rocky mountain endolithic microbial ecosystems. Appl. Environ. Microbiol. 73, 3497-3504. doi: 10.1128/AEM.02656-06

Weyens, N., Thijs, S., Popek, R., Witters, N., Przybysz, A., Espenshade, J., et al. (2015). The role of plant-microbe interactions and their exploitation for phytoremediation of air pollutants. Int. J. Mol. Sci. 16, 25576-25604. doi: 10. 3390/ijms161025576

Weyens, N., van der Lelie, D., Taghavi, S., Newman, L., and Vangronsveld, J. (2009a). Exploiting plant-microbe partnerships to improve biomass production and remediation. Trends Biotechnol. 27, 591-598. doi: 10.1016/j.tibtech.2009. 07.006

Weyens, N., van der Lelie, D., Taghavi, S., and Vangronsveld, J. (2009b). Phytoremediation: plant-endophyte partnerships take the challenge. Curr. Opin. Biotechnol. 20, 248-254. doi: 10.1016/j.copbio.2009. 02.012

Wickham, H. (2016). Elegant Graphics for Data Analysis. New York, NY: SpringerVerlag.

Zhang, H. H., Chen, S. N., and Huang, T. L. (2015). Structure and functional metabolism of bacterial communities on leaves of typical urban greening tree species. Polish J. Environ. Stud. 24, 823-828. doi: 10.15244/pjoes/ 30592

Zhu, Y., Hinds, W. C., Kim, S., Shen, S., and Sioutas, C. (2002). Study of ultrafine particles near a major highway with heavy-duty diesel traffic. Atmos. Environ. 36, 4323-4335. doi: 10.1016/S1352-2310(02)00354-0

Conflict of Interest Statement: The authors declare that the research was conducted in the absence of any commercial or financial relationships that could be construed as a potential conflict of interest.

Copyright (c) 2019 Espenshade, Thijs, Gawronski, Bové, Weyens and Vangronsveld. This is an open-access article distributed under the terms of the Creative Commons Attribution License (CC BY). The use, distribution or reproduction in other forums is permitted, provided the original author(s) and the copyright owner(s) are credited and that the original publication in this journal is cited, in accordance with accepted academic practice. No use, distribution or reproduction is permitted which does not comply with these terms. 